Article

\title{
Germination Patterns in Seeds Produced in Apical and Basal Fruits of Two Thlaspi arvense Populations
}

\author{
Eva Edo-Tena ${ }^{1}$, Russ W. Gesch ${ }^{2}$ and Aritz Royo-Esnal 1,*(D) \\ 1 Department of Horticulture, Botany and Landscaping, Agrotecnio, University of Lleida, 25198 Lleida, Spain; \\ evaedotena@hbj.udl.cat \\ 2 United States Department of Agriculture, Agricultural Research Service, Morris, MN 56267, USA; \\ russ.gesch@usda.gov \\ * Correspondence: aritz.royo@udl.cat
}

Received: 8 April 2020; Accepted: 21 May 2020; Published: 25 May 2020

\begin{abstract}
The aim of the present work is to study possible differences in the germination behavior of apical and basal seeds (produced in the upper and lower fruits of the infruitescence), of two populations of field pennycress (Thlaspi arvense), both produced in a Mediterranean and a continental temperate climate. The results showed that among the three studied factors (population, seed type, production site), only the production site was relevant for the total germination, germinating those produced in Morris in a greater amount than those produced in Lleida. Germination models could be applied only to seeds produced at Morris ( $>10 \%$ germination), and despite the lack of differences in the total germination percentage, germination rates (speed- $b$ parameter-and time to $50 \%$ germination $-\mathrm{G}_{50}$ ) differed between population and seed types-apical seeds from the Spanish population germinated faster (lower $b$ parameter) than the rest, while apical seeds of both populations germinated faster than the corresponding basal seeds (lower $\mathrm{G}_{50}$ ). The results show, on the one hand, the importance of the seed production site if this species was considered as a commercial oilseed crop and, on the other hand, differences that will help seed selection for seed germination and establishment improvement of pennycress.
\end{abstract}

Keywords: germination rate; field pennycress; oilseed crop; seed origin; seed type

\section{Introduction}

Thlaspi arvense (field pennycress) is a weed that had relative importance in the past [1] when it caused yield losses in wheat [2] of up to 45\% [3] when it appeared with fixweed (Desurainia sophia); it still remains categorized as a noxious weed in the state of Michigan (USA) and in Manitoba (Canada) [4]. On the contrary, it has become a rare species in Spain [2], probably due to the huge agronomic pressure [5] in the last 50 years. It belongs to the Brassicaceae family, like oilseed rape (Brassica napus L.), which is an important oilseed crop [6]. Like rapeseed, it shares oilseed characteristics that make it a promising source for biofuel feedstock [7] and other industrial applications like paints or varnishes [8]. Pennycress can be integrated into cropping systems as a cash cover crop [9,10], and recently, it has also been demonstrated that it can feasibly be double-cropped with annual summer crops in the Mediterranean region [11]. Previously, a model for the field emergence of pennycress was developed [12], and its fitness was evaluated under the Mediterranean and continental temperate conditions [13] to gain knowledge for its management for conservation purposes (e.g., in Spain) and as a potential oilseed crop.

Knowledge about the germination characteristics of seeds helps to understand factors affecting them, and hence, crop establishment [14]. This knowledge may help enhance crop improvement. Seed position in the mother plant can affect the germination characteristics and requirements of 
seeds [15]. Among the Brassicaceae species, seed position has been demonstrated to have relevant influence on the oil content in field pennycress [16]. Moreover, seed oil content has been shown to have a crucial effect. For example, low seed oil content was associated with a decrease in the germination and emergence of Arabidopsis thaliana [17], another Brassicaceae species closely related to pennycress. Despite this, Gesch et al. [18] did not observed clear germination differences between seeds produced in the apical and basal fruits of two populations of field pennycress. On the other hand, environmental conditions that the mother plant is exposed to could also affect the germination capability of the seeds produced [19]. Menegat et al. [19] found that the environmental conditions during the reproductive growth of the mother plant affected the dormancy level of seeds in Alopecurus myosuroides. Specifically, they demonstrated that higher seed dormancy levels were associated with lower soil moisture seven to 35 days before shedding seeds, and higher temperature accumulation zero to seven days before shedding than seeds produced under more humid, mild climatic conditions Similarly, Gesch et al. [18] observed that pennycress seeds produced in plants grown in a semiarid Mediterranean climate presented higher dormancy levels than plants produced in a continental temperate climate, even if the mother plants grown under both climates originated from the same populations of seeds.

The objective of this work is to complete the results obtained by Gesch et al. [18], in which the germination of two populations of pennycress was studied, and develop a germination model that could help establish laboratory trials and field emergence programs for better management of this crop.

\section{Materials and Methods}

\subsection{Cultural Practices, Site Description}

Pennycress seeds were harvested from mature plants in Morris, Minnesota USA $\left(45^{\circ} 43^{\prime} 36^{\prime \prime}\right.$ $\left.\mathrm{N}-95^{\circ} 49^{\prime} 17^{\prime \prime} \mathrm{W}\right)$ and Camarillas, Teruel, Spain $\left(40^{\circ} 38^{\prime} 39^{\prime \prime} \mathrm{N}-0^{\circ} 48^{\prime} 35^{\prime \prime} \mathrm{W}\right)$, between June and July 2012. The seeds that were sown and harvested in Morris in 2012 were originally collected from a farmer's field near Peoria, IL. After harvest, seeds were left air-dried for one week and dry stored in plastic pots under laboratory conditions, between 21 and $25^{\circ} \mathrm{C}$ in darkness, until they were sown for the study in early autumn. Seeds of the two populations, American (Morris) and Spanish (Teruel), were shared, and both seed populations were sown for the study at each field site. The field site in Spain was at Almenar $\left(41^{\circ} 46^{\prime} 36^{\prime \prime} \mathrm{N}-0^{\circ} 32^{\prime} 7^{\prime \prime} \mathrm{E}\right)$ and in the USA was at Morris (same as above). Spring wheat (Triticum aestivum L.) was the previous crop at both sites.

Experimental plots were of $1 \mathrm{~m}^{2}$ and organized into a randomized complete block design with four replicates, where 1,000 seeds plot ${ }^{-1}$ were sown at a depth of $1 \mathrm{~cm}$ in four 250 -seed row $^{-1}$ spaced $25 \mathrm{~cm}$ apart. This way, the cultivation was relatively simulated, and it facilitated hand-weeding. Seeds were sown on 18 September 2012 at Morris and on 4 October 2012 at Almenar.

As described in Gesch et al. [18], 10 to 25 randomly chosen mature plants were harvested from each plot and brought to the laboratory for processing. The harvest took place on 3 July 2013 in Almenar and on 9 July 2013 at Morris. Seeds of pennycress were harvested selectively from mature apical and basal silicles of infructescences. For each plant harvested, the seven upper-most silicles on the main stem raceme were chosen as the "apical fruits", while seven lower-most silicles on the main stem were chosen as the "basal fruits." These seeds were stored dry and later used in germination experiments.

\subsection{Germination Study}

The germination tests were conducted in Lleida, Spain, during 2013 and 2014. Seeds, previously sterilized in 10\% hypochlorite sodium for $1 \mathrm{~min}$, were placed in germination chambers under a controlled environment, at constant temperatures of $5,8,11,14,17$, and $20^{\circ} \mathrm{C}$ in the dark. Twenty five seeds, with four replicates from each apical and basal seed from each population were placed in Petri dishes on a medium of $1.5 \%$ agar and stored at each constant temperature. The number of germinated seeds was counted daily for $21 \mathrm{~d}$ under a green light. This experiment was repeated twice from September to December 2013 and finished in January 2014. 


\subsection{Statistical Analysis}

The differences in the germination percentage between the constant temperatures were already published by Gesch et al. [18]. Despite that there were some differences, if the average of all the temperatures was considered together, the results are similar to those obtained for the emergence under field conditions by Royo-Esnal et al. [12]. For this reason, to better understand the population characteristics as a whole, data for percent germination at the constant temperatures were combined for each pennycress population, the origin of the seeds, and the production site. These data were subjected to three-way ANOVA, with seed population, origin and type as fixed factors, and subsequent LSD test if there were no interactions between the factors and differences that appeared, with previous transformation to $\operatorname{arcsen} \sqrt{x}$ if the normality and homoscedascity were not accomplished. If there were interactions among factors, these were separated, and two-way ANOVAs were applied. If the interactions persisted, one-way ANOVAs were applied.

A first estimation of the base temperature $\left(\mathrm{T}_{\mathrm{b}}\right)$ was performed for each seed type. This estimation was performed by calculating the inverse of the time (days) needed for $50 \%$ of germination $\left(\mathrm{G}_{50}\right)$ at each of the six constant temperatures, as described by Bradford [20]. The points were then regressed against temperature with a linear regression (1) and the intersect with 0 was used as $\mathrm{T}_{\mathrm{b}}$ for calculating the growing degree days (GDD) for each seed type. For the $\mathrm{G}_{50}$ estimation, the Boltzmann sigmoidal function (2) was applied to each type of seed and population at each temperature.

$$
Y=a x+b
$$

where $a$ is the germination rate and $b$ is a constant.

$$
Y=A /\left\{1+\exp \left[2 \times \ln (9) \times\left(\mathrm{G}_{50}-\mathrm{GDD}\right) / b\right]\right\}
$$

where $Y$ is the percent seed germination, GDD is the accumulated growing degree days, $A$ is the percent maximum germination, $\mathrm{G}_{50}$ is the growing degree in days from the start of the experiment to $50 \%$ of maximum germination, and $b$ is growing degree in days from 10 to $90 \%$ of maximum germination [21].

Data of the cumulative germination was then expressed against growing degree days (GDD), which was estimated as follows (3):

$$
G D D=\Sigma\left(T_{i}-T_{b}\right)
$$

where $T_{i}$ is the corresponding growth chamber temperature $\left(5\right.$ to $20^{\circ} \mathrm{C}$ ), and $T_{b}$ is the previously estimated base temperature for the corresponding seed type (apical or basal) and population (Teruel or Morris). The maximum germination percentage was normalized to $100 \%$, and the Boltzmann function (2) was applied again to estimate the parameters that describe the germination rate of pennycress seeds. Germination rate was estimated using JMP 11 (SAS Inst. Inc., Cary, NC, USA).

\section{Results}

\subsection{Climate}

The climatic conditions from the sowing of field pennycress to harvest at each experimental site were published in Gesch et al. [18]. Here, we very briefly summarize the most important aspects of that season (Table 1), which were the mean temperatures of $3.8^{\circ} \mathrm{C}$ and $10^{\circ} \mathrm{C}$, respectively, for Morris and Almenar; the accumulated GDD from sowing to harvest was also lower in Morris $\left(1,198^{\circ} \mathrm{C}\right)$ compared to Almenar $\left(1,387^{\circ} \mathrm{C}\right)$; and despite the similar overall precipitation, there had been a difference in its distribution, as at Morris, only $61 \mathrm{~mm}$ fell between September and January, and $310 \mathrm{~mm}$ between February and July; while at Almenar, the precipitation amount was $209 \mathrm{~mm}$ and 210 for these same periods (Table 1). 
Table 1. Monthly climate data for Almenar, Spain, and Morris, Minnesota USA, during the growing season of pennycress from sowing to harvest in 2012-2013. Tm, mean temperature; GDD, accumulated growing degree days; $\mathrm{P}$, precipitation; Day, mean daylength.

\begin{tabular}{|c|c|c|c|c|c|c|c|c|}
\hline \multirow[b]{2}{*}{ Month } & \multicolumn{4}{|c|}{ Morris, Minnesota USA } & \multicolumn{4}{|c|}{ Almenar Spain } \\
\hline & $\operatorname{Tm}\left({ }^{\circ} \mathrm{C}\right)$ & $\begin{array}{l}\text { GDD } \\
\left({ }^{\circ} \mathrm{C} \mathrm{d}\right)\end{array}$ & $\mathbf{P}(\mathbf{m m})$ & Day (h) & $\operatorname{Tm}\left({ }^{\circ} \mathrm{C}\right)$ & $\begin{array}{l}\text { GDD } \\
\left({ }^{\circ} \mathrm{C} \mathrm{d}\right)\end{array}$ & $\mathbf{P}(\mathrm{mm})$ & Day (h) \\
\hline September & 15.5 & 349 & 0 & 12.3 & 19.6 & 479 & 49 & 12.2 \\
\hline October & 7.0 & 112 & 29 & 10.6 & 15.2 & 362 & 92 & 10.8 \\
\hline November & 0.2 & 15 & 16 & 9.3 & 9.2 & 166 & 30 & 9.6 \\
\hline December & -8.3 & 2 & 5 & 8.6 & 5.6 & 73 & 7 & 9.1 \\
\hline January & -10.8 & 0 & 11 & 9.0 & 4.6 & 35 & 31 & 9.4 \\
\hline February & -10.3 & 0 & 0 & 10.1 & 5.4 & 60 & 8 & 10.4 \\
\hline March & -6.8 & 0 & 33 & 11.7 & 9.2 & 169 & 68 & 11.7 \\
\hline April & 1.8 & 38 & 16 & 13.3 & 11.7 & 237 & 78 & 13.1 \\
\hline May & 13.1 & 292 & 61 & 14.7 & 13.0 & 284 & 14 & 14.3 \\
\hline June & 19.3 & 456 & 179 & 15.4 & 19.2 & 469 & 37 & 15.0 \\
\hline July & 24.1 & 177 & 21 & 15.1 & 24.7 & 192 & 5 & 14.7 \\
\hline Total & & 1441 & 371 & & & 2526 & 419 & \\
\hline
\end{tabular}

\subsection{Total Germination}

The three-way ANOVA showed no interactions among factors, and thus, the final results can be clearly interpreted (Table 2). The analysis showed that seeds produced in Morris germinated significantly more (average between 36.8-76.2\%) than seeds produced in Almenar (average between $1.4-5.5 \%$ ), but there were no significant differences between seed origin (Teruel vs. Morris) or seed type (apical vs. basal), even when produced at Morris, where more than $70 \%$ of the seeds from the Teruel population germinated, and seeds from the Morris population did not reach $50 \%$ of germination. For more detailed information, see Gesch et al. [18]. For this reason, the subsequent analysis for the germination modeling was performed with seeds of both populations from Teruel and Morris produced at Morris.

Table 2. Average germination percentages ( \pm standard error) for each type of seed produced by each T. arvense population at each site that was produced. Residuals, $F$ of Fisher, and probability $(p)$ resulted from the three-way ANOVA are also provided. ${ }^{* *}$, significant differences $(p<0.05)$.

\begin{tabular}{cccccc}
\hline Origin (Population) & Production Site & Apical & Basal & $\boldsymbol{F}$ & $\boldsymbol{p}$ \\
\hline Teruel & Almenar (Spain) & $5.3 \pm 2.3$ & $1.4 \pm 0.4$ & & \\
Morris & Almenar (Spain) & $5.5 \pm 1.3$ & $2.8 \pm 0.8$ & & \\
Teruel & Morris (USA) & $72.3 \pm 4.8$ & $76.2 \pm 5.3$ & & \\
Morris & Morris (USA) & $46.3 \pm 6.8$ & $36.8 \pm 7.2$ & & \\
Production site (PS) & & 21625.652 & 21625.652 & 90.244 & $<0.001^{* *}$ \\
Seed origin (SO) & & 223.07 & 223.07 & 0.931 & 0.341 \\
Seed type (ST) & & 99.453 & 99.453 & 0.415 & 0.523 \\
PS $\times$ SO & 291.128 & 291.128 & 1.215 & 0.277 \\
PS $\times$ ST & 0.969 & 0.969 & 0.00404 & 0.950 \\
So $\times$ ST & & 423.638 & 423.638 & 1.768 & 0.191 \\
PS $\times$ So $\times$ ST & & 352.526 & 352.526 & 1.471 & 0.232 \\
Residual & & 9345.745 & 239.634 & & \\
Total & 45792.077 & 995.48 & & \\
\hline
\end{tabular}

\subsection{Base Temperatures, Germination Rates, and Modeling}

Seeds produced in Almenar showed lower than $10 \%$ germination, except the apical seeds at $5{ }^{\circ} \mathrm{C}$ and at $8{ }^{\circ} \mathrm{C}$, and thus, were considered dormant [22]. For this reason, $\mathrm{T}_{\mathrm{b}}$ was estimated for seeds 
produced in Morris for both Teruel and Morris origin, and consequently, germination models were developed only for these seeds.

The regression line applied to the $1 / G_{50}$ to each type of seed (Figure 1), namely apical and basal seeds from Teruel and Morris populations, produced at Morris, showed that the base temperature was similar for each type of seed in pennycress, being $1.29^{\circ} \mathrm{C}$ and $1.62{ }^{\circ} \mathrm{C}$, respectively for the basal and apical seeds in the Teruel population, and $2.13^{\circ} \mathrm{C}$ and $2.49^{\circ} \mathrm{C}$ respectively for the Morris population. These $T_{b}$ values permitted the estimation of the GDD, and consequent modeling of the germination for these populations and seed types.

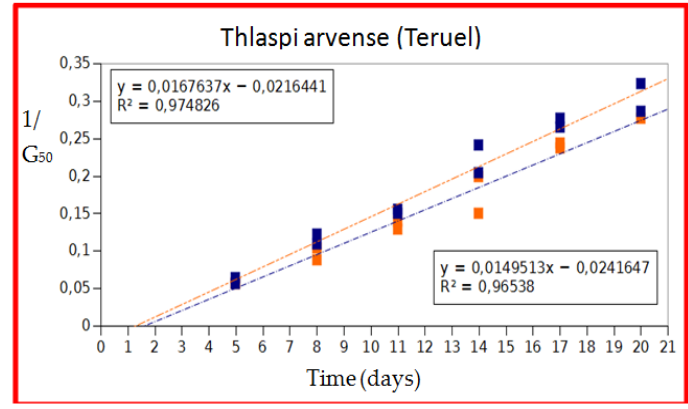

(a)

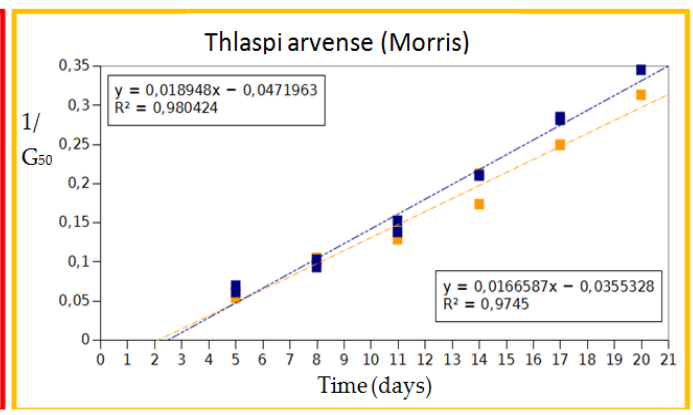

(b)

Figure 1. Inverse of the time (in days) for 50\% of germination (G50) of the Teruel (a) and Morris (b) seeds. Orange quadrats, basal seeds; blue quadrats, apical seeds. The regression line for each type of seed is also provided, as well as the intersection that would correspond to the base temperature $\left(\mathrm{T}_{\mathrm{b}}\right)$ for each one.

Figures 2 and 3 show the cumulative percentage of germination for each type of seed in a sequence from the day-based graph to the GDD-based graph, and to normalized germination percentage GDD-based graph. Day-based graphs reflect the delay in the germination of those seeds exposed to low temperatures, being the slowest germination at $5^{\circ} \mathrm{C}$, followed by $8{ }^{\circ} \mathrm{C}, 11^{\circ} \mathrm{C}$, and $14{ }^{\circ} \mathrm{C}$ (Figure $2 \mathrm{a}, \mathrm{b}$ and Figure $3 \mathrm{a}, \mathrm{b}$ ), while the time for germination was fastest and similar at $17^{\circ} \mathrm{C}$ and $20^{\circ} \mathrm{C}$. The next step was to transform days into GDD, using the corresponding estimated $\mathrm{T}_{\mathrm{b}}$ for each type of seed (Figure 1 ). This transformation equalized the time needed for germination at each temperature (Figure 2c, $d$ and Figure $3 c, d$ ) in all cases. Finally, when the highest germination was normalized to $100 \%$ in each case, the cumulative emergence at each temperature overlapped and allowed the application of a thermal time germination model for each type of seed (Figure 2e,f and Figure 3e,f). The Boltzmann model was accurately applied, with an $\mathrm{R}^{2}$ between 0.97 and 0.99 in all cases (Table 3).

Table 3. Model parameters for the Boltzmann function applied to the normalized germination percentages in Figure 2; Figure 3 to the apical and basal seeds from Teruel and Morris produced in Morris (Minnesota), and the corresponding $\mathrm{R}^{2}$ for the developed model. The standard error for each parameter is provided, as well as the results of the comparison between apical and basal seeds for each seed population (Teruel and Morris). Different letters denote significant differences $(p<0.05)$.

\begin{tabular}{cccc}
\hline Seed Type & $\boldsymbol{b}$ & $\boldsymbol{G}_{\mathbf{5 0}}$ & $\mathbf{R}^{\mathbf{2}}$ \\
\hline Apical Teruel & $27.1467 \pm 1.4485 \mathrm{~B}$ & $55.0059 \pm 0.3731 \mathrm{~B}$ & 0.98 \\
Basal Teruel & $40.9301 \pm 2.9071 \mathrm{~A}$ & $69.4624 \pm 0.7351 \mathrm{~A}$ & 0.97 \\
Apical Morris & $36.3481 \pm 1.6255 \mathrm{~A}$ & $55.9576 \pm 0.4223 \mathrm{~B}$ & 0.99 \\
Basal Morris & $38.9513 \pm 2.1679 \mathrm{~A}$ & $59.1616 \pm 0.5664 \mathrm{~A}$ & 0.98 \\
\hline
\end{tabular}




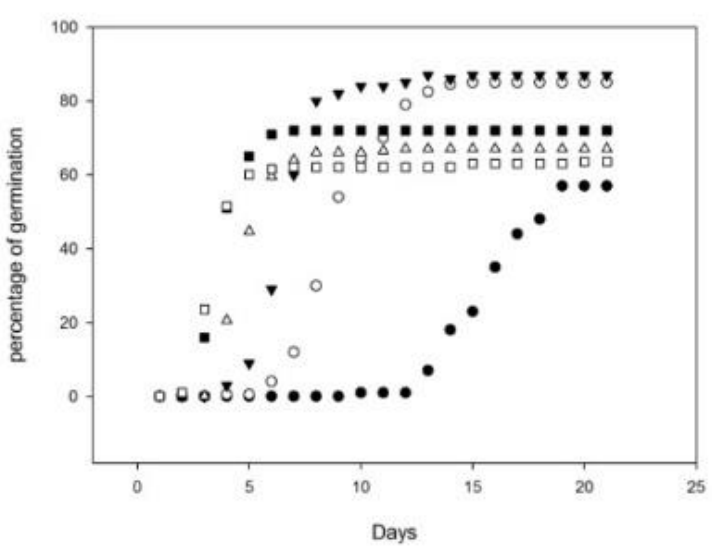

(a)

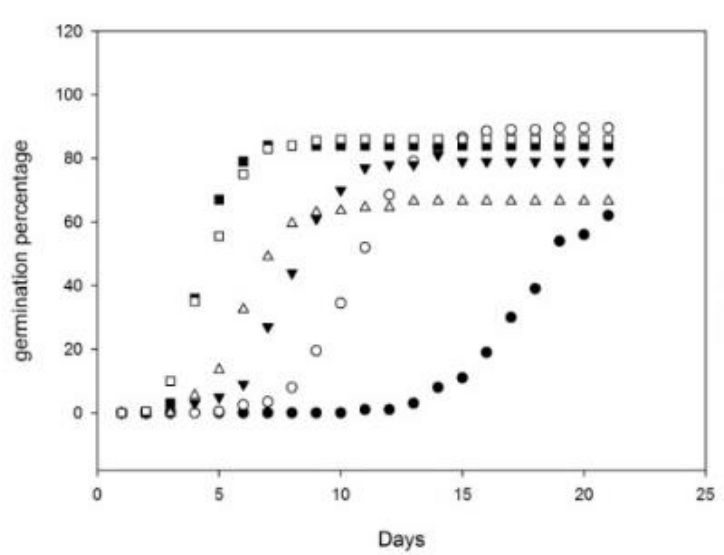

(b)

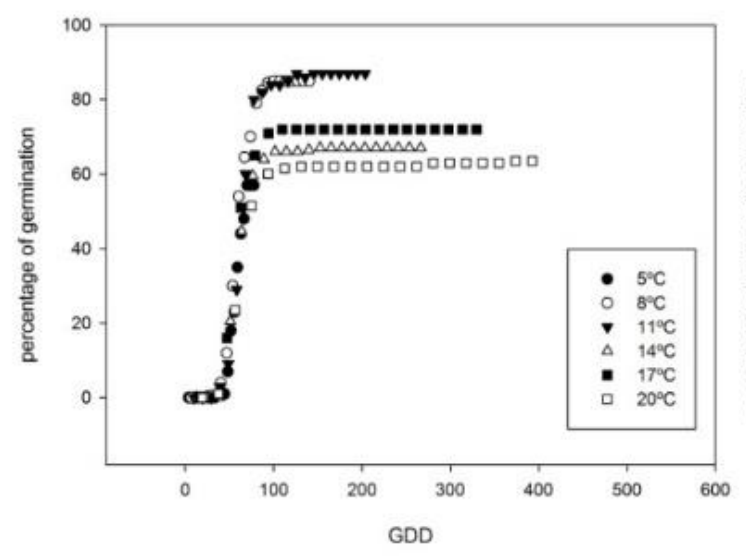

(c)

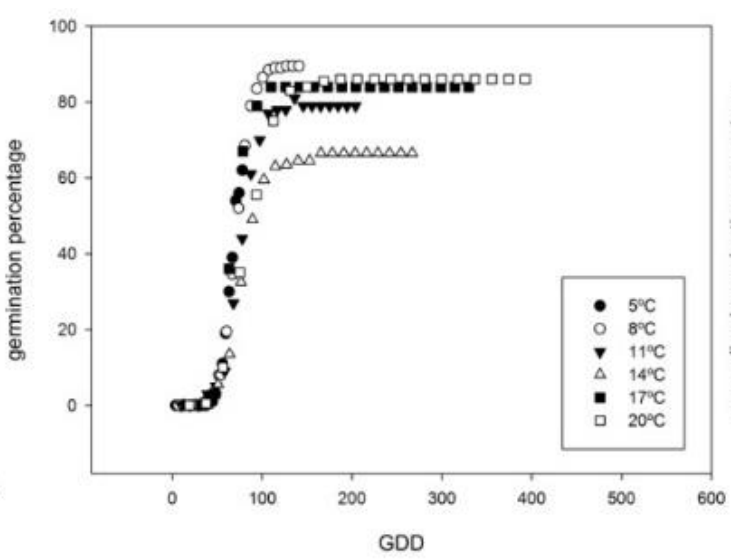

(d)

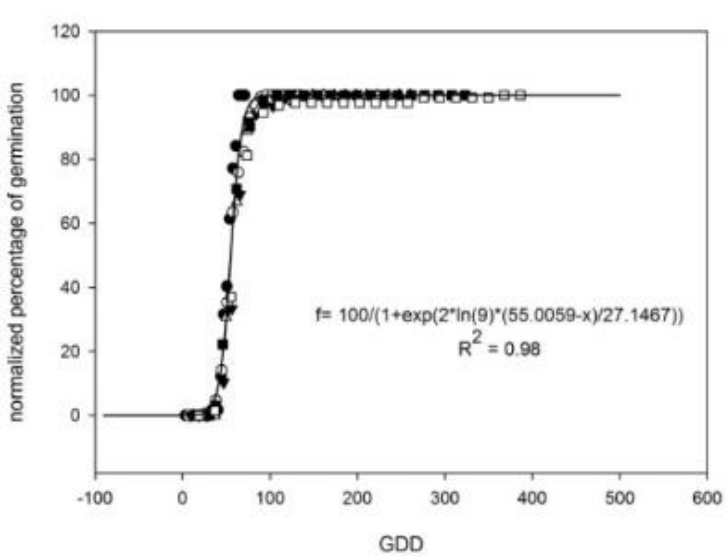

(e)

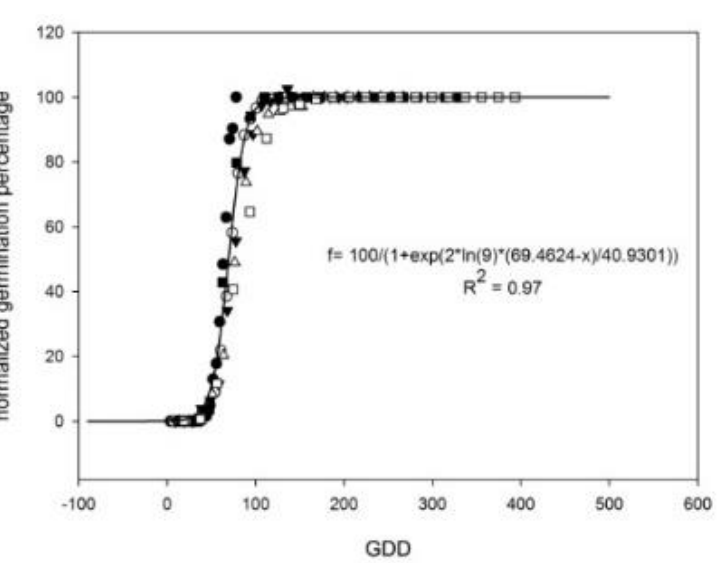

(f)

Figure 2. Cumulative germination seeds of Thlaspi arvense from Teruel produced at Morris. (a), apical, and (b), basal, seed germination percentages are shown against days after sowing; (c), apical, and (d), basal seed germination percentages shown against growing degree days $\left(\mathrm{T}_{\mathrm{b}}=1.29{ }^{\circ} \mathrm{C}\right.$ and $1.62{ }^{\circ} \mathrm{C}$, respectively, for basal and apical seeds); (e), apical, and (f), basal seed germination percentages as shown as normalized values to $100 \%$. In (e) and (f), the Boltzmann formula for the germination model is provided for both apical and basal seeds, respectively, with the corresponding $\mathrm{R}^{2}$. 


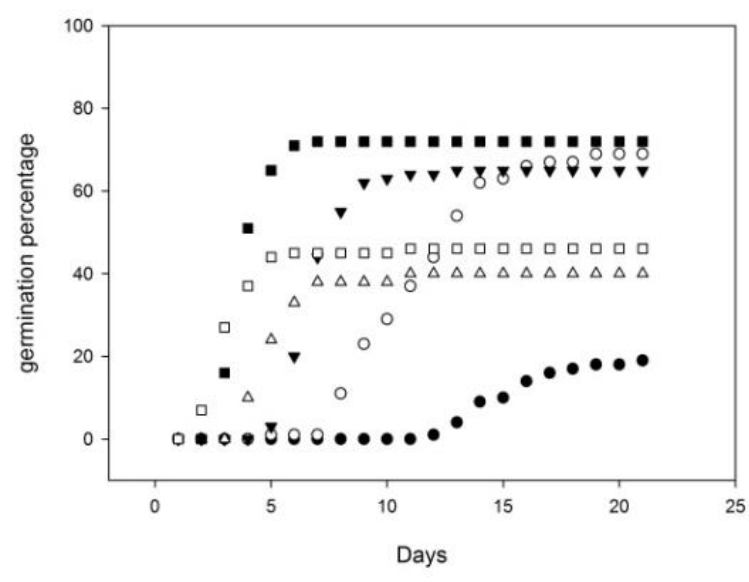

(a)

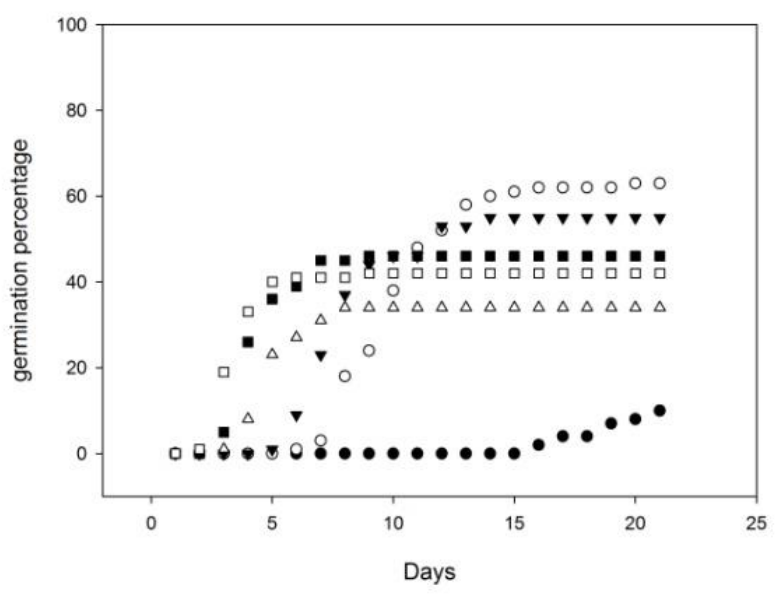

(b)

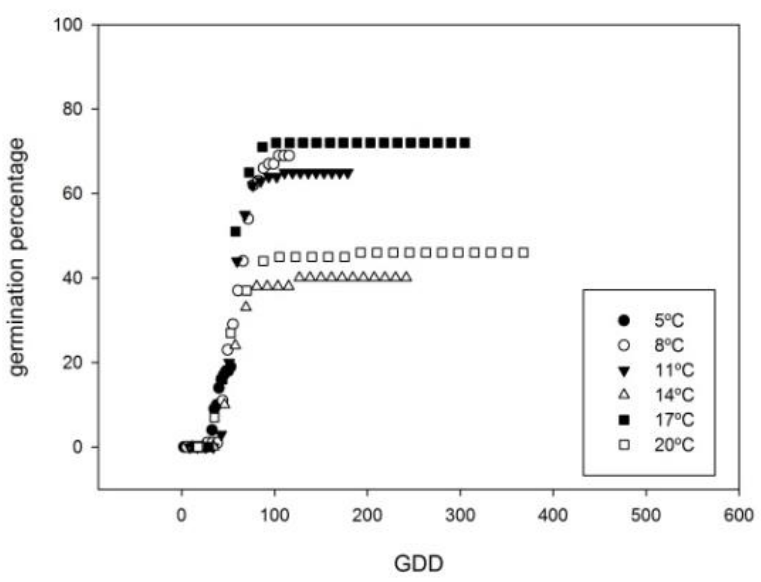

(c)

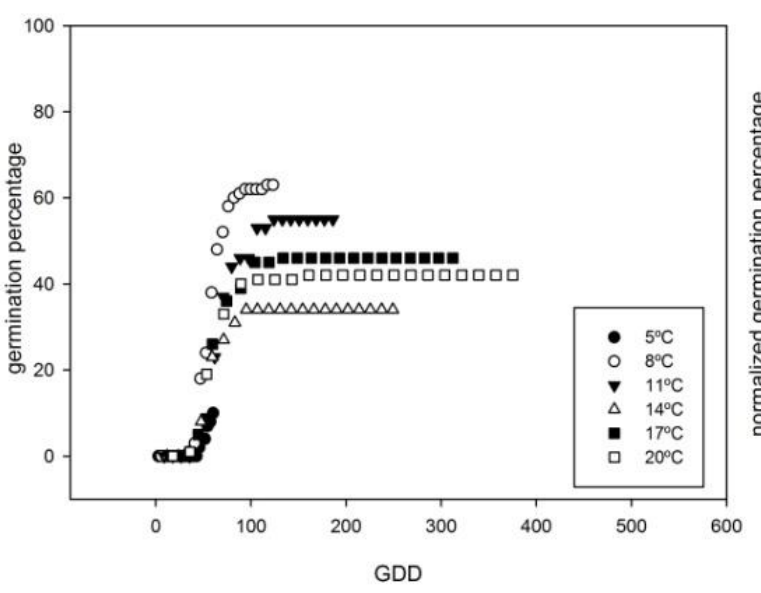

(d)

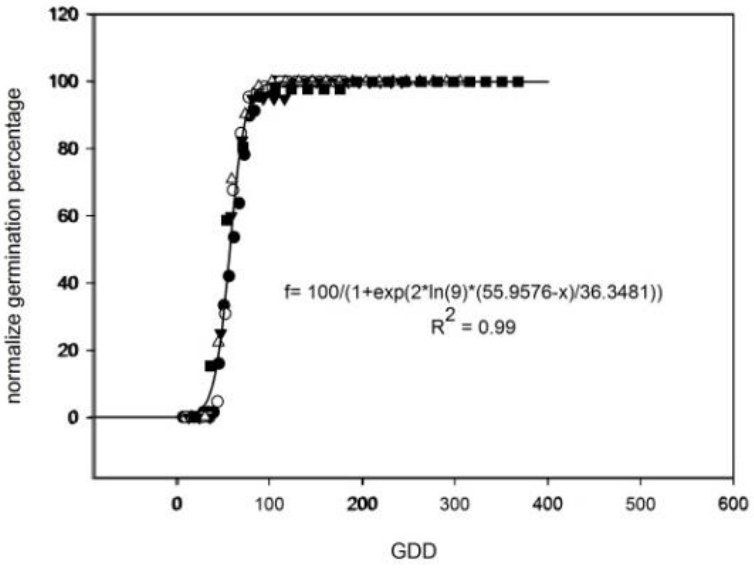

(e)

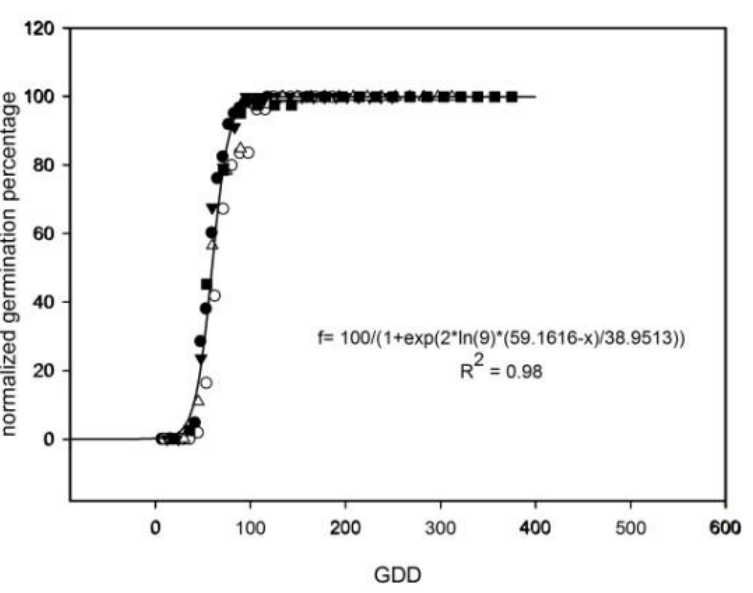

(f)

Figure 3. Cumulative germination seeds of Thlaspi arvense from Morris produced at Morris. (a), apical, and (b), basal, seed germination percentages are shown against days after sowing; (c), apical, and (d), basal seed germination percentages shown against growing degree days $\left(\mathrm{Tb}=2.13{ }^{\circ} \mathrm{C}\right.$ and $2.49^{\circ} \mathrm{C}$, respectively, for basal and apical seeds); (e), apical, and (f), basal seed germination percentages shown as normalized values to $100 \%$. In (e) and (f), the Boltzmann formula for the germination model is provided for both apical and basal seeds, with the corresponding $\mathrm{R}^{2}$. 
The comparison of the $b$ and $\mathrm{G}_{50}$ parameters of the Boltzmann model showed that these were significantly different between apical and basal seeds of the Teruel population, the former germinating earlier $\left(55.0^{\circ} \mathrm{C}<69.5^{\circ} \mathrm{C}, \mathrm{G}_{50}\right.$ or GDD for $50 \%$ of germination) and faster $\left(b 27.1^{\circ} \mathrm{C}<40.9^{\circ} \mathrm{C}\right.$, GDD from $10 \%$ to $90 \%$ of germination). For the Morris population, only the $\mathrm{G}_{50}$ was significantly different between apical and basal seeds, while parameter $b$ was not statistically different (Table 3 ).

\section{Discusion}

Seeds of both populations germinated better when produced at Morris than when produced at Almenar, with significant differences between production sites for the same populations [18]. The maternal effect understood as the environmental conditions (climatic and edaphic) at each site the plant was subjected to during seed development seems to be the reason for these results. Baskin and Baskin [15] point out that the seed dormancy level can vary between different populations of the same species; but in our case, differences have been observed within the same populations grown in different sites. Menegat et al. [19] demonstrated that soil water potential and temperature during the reproductive growth of Alopecurus myosuroides was responsible for the dormancy level of the seeds it produced. As both populations were sown during the same growing season in Almenar and Morris, the environmental conditions of the 2012-2013 season were the primary factors that conditioned the germination (and dormancy level) of the seeds produced by the plants. Some authors affirm that seeds produced at sites with a higher number of daylight hours germinate better than those produced in sites where days are shorter (various authors in Baskin and Baskin [15]). In this study, daylength during seed production, between April and June, is longer in Morris $\left(45^{\circ} 43^{\prime}\right)$ than in Almenar $\left(41^{\circ} 46^{\prime}\right)$ (Table 1 ). However, climatic conditions also resulted in different GDD accumulation. For instance, at Almenar, from sowing to harvest, plants accumulated $1386^{\circ} \mathrm{C}$ days, while in Morris, they accumulated $1198^{\circ} \mathrm{C}$ days. Conversely, during seed production at each site (April-May in Almenar and May-June in Morris), rainfall was $92 \mathrm{~mm}$ in Almenar, while in Morris, it rained $240 \mathrm{~mm}$ (Table 1). Thus, a combination of these environmental conditions would explain the differences in the germination percentage, and hence, the dormancy level obtained in seeds produced in each site.

Additionally, seeds produced in fruiting bodies on different parts of the mother plant stem also showed differences in germination behavior. Apical seeds tended to present lower base temperature for germination (Figure 1) and germinated earlier and faster (Table 2) than basal seeds. However, these differences were not always significant, as demonstrated for $G_{50}$ (parameter $c$, Table 2) for the Morris population. These differences in germination characteristics between apical and basal seeds are common, although not always in the same way. For instance, apical seeds of Plantago coronopus germinate later than the basal seeds [23], and the same happened in Ambrosia species [24].

These results indicate that although the final percentage of germination was similar between the two seed types [18], dormancy levels differed between apical and basal seeds due to maternal influence, which affected their germination rate. Those seeds that were produced first (basal ones) acquire a stronger inherent dormancy that persists longer than those seeds produced later (apical ones). In the particular case of these pennycress populations, despite the similarities of some values, significant differences appeared between them, which was a consequence of the exhaustive harvest performed for the seed selection, and the homogeneity showed by each of these seed groups. The apical seeds from the Spanish population showed a lower $b$ value, which means higher seed germination, and thus, more synchronicity. Apical seeds of both populations also germinated earlier than basal seeds. Both earlier and faster germination are desirable characteristics for the establishment of a crop, as usually are related to better growth and larger seed production [25]. This information could be of value in order to select seeds for improved germination and crop establishment. The differences between populations are also relevant, indicating that some accessions might be more amenable for cultivation. For example, the seeds of the Spanish population produced at Morris germinated to a greater extent, and those apical ones, earlier and faster, and could be considered more suitable for breeding programs than the basal ones, which lasted more time and germinated in a slower rate, even 
than the American population. As a consequence, four germination models have been developed, one for each population and seed type. These models contribute to a better understanding of pennycress seed germination behavior and add to the knowledge acquired with the emergence model developed by Royo-Esnal et al. [12]. In contrast to these authors, who worked with a seed mixture from the whole population (i.e., the mixture of apical, medium, and basal seeds), in the present study, only apical and basal seeds of the main stem were used, thus, this information, although valuable, must be used with caution. Nevertheless, results are highly useful for research focused on seed selection for improving seed germination and the establishment of pennycress.

Author Contributions: Conceptualization, A.R.-E., and R.W.G.; Data curation, A.R.-E., and E.E.-T. Formal analysis, A.R.-E., and E.E.-T.; Funding acquisition, A.R.-E.; Investigation, A.R.-E., E.E.-T. and R.W.G.; Methodology, A.R.-E., and R.W.G.; Project administration, A.R.-E.; Supervision, A.R.-E.; Writing—original draft, A.R.-E.; Writing一review and editing, A.R.-E., R.W.G. All authors have read and agreed to the published version of the manuscript.

Funding: This work was financed, in part, by the grant given to Eva Edo-Tena by the Spanish Weed Science Society (SEMh), as well as by the Spanish Ministry of Science and Innovation (MICIIN) AGL2010-22084-C02-01 Plan Nacional I+D+I (MICIIN).

Conflicts of Interest: The authors declare no conflict of interest.

\section{Abbreviations}

d: days: GDD: Growing Degree Days; LSD: Least Significant Difference.

\section{References}

1. Best, K.F.; McIntyre, G.I. The biology of Canadian weeds 9. Thlaspi arvense L. Can. J. Plant Sci. 1975, 55, 279-292. [CrossRef]

2. Blackshaw, R.E. Control of stinkweed (Thlaspi arvense) and flixweed (Descurainia sophia) in winter wheat (Triticum aestivum). Can. J. Plant Sci. 1990, 70, 817-824. [CrossRef]

3. Aoki, M.; Asai, M. Emergence and control of naturalized weeds, Camelina microcarpa Andrz. ex DC., Descurainia sophia (L.) Webb ex Prantl, and Thlaspi arvense L., in wheat fields in Nagano Prefecture. J. Weed Sci. Technol. 2016, 61, 139-148. [CrossRef]

4. Sedbrook, J.C.; Phippen, W.B.; Marks, M.D. New approaches to facilitate rapid domestication of a wild plant to an oilseed crop: Example pennycress (Thlaspi arvense). Plant Sci. 2014, 227, 122-132. [CrossRef]

5. Cirujeda, A.; Aibar, J.; Zaragoza, C. Remarkable changes of weed species in Spanish cereal fields from 1976 to 2007. Agron. Sustain. Dev. 2011, 31, 675-688. [CrossRef]

6. Zanetti, F.; Monti, A.; Berti, M.T. Challenges and opportunities for new oilseed crops in EU-27: A review. Ind. Crop. Prod. 2013, 50, 580-595. [CrossRef]

7. Sindelar, A.J.; Schmer, M.R.; Gesch, R.W.; Forcella, F.; Eberle, C.A.; Thom, M.D.; Archer, D.W. Winter oilseed production for biofuel in the US Corn Belt: Opportunities and limitations. GCB Bioenergy 2017, 9, 508-524. [CrossRef]

8. Walsh, M.E. Potential New Bioenergy and Bioproducts Crops. Sun Grant Bioweb. Available online: http://bioweb.sungrant.org (accessed on 2 December 2019).

9. Wortman, S.E. Field pennycress (Thlaspi arvense L.) has potential as an interseed cover crop. Renew. Agric. Food Syst. 2019, 1-5. [CrossRef]

10. Cubins, J.A.; Wells, M.S.; Frels, K.; Ott, M.A.; Forcella, F.; Johnson, G.; Walia, M.K.; Becker, R.L.; Gesch, R.W. Managemente of pennycress as a winter annual cash cover crop. A review. Agron. Sustain. Dev. 2019, 39, 46. [CrossRef]

11. Zanetti, F.; Isbell, T.A.; Gesch, R.W.; Evangelista, R.L.; Alexopoulou, E.; Moser, B.; Monti, A. Turning a burden into an opportunity: Pennycress (Thlaspi arvense L.) a new oilseed crop for biofuel production. Biomass Bioenergy 2019, 130, 105354. [CrossRef]

12. Royo-Esnal, A.; Necajeva, J.; Torra, J.; Recasens, J.; Gesch, R.W. Emergence of field pennycress (Thlaspi arvense L.): Comparison of two accessions and modelling. Ind. Crop. Prod. 2015, 66, 161-169. [CrossRef]

13. Royo-Esnal, A.; Edo-Tena, E.; Torra, J.; Recasens, J.; Gesch, R.W. Using fitness parameters to evaluate three oilseed Brassicaceae species as potential oil crops in two contrasting environments. Ind. Crop. Prod. 2017, 95, 148-155. [CrossRef] 
14. Gardarin, A.; Coste, F.; Wagner, M.H.; Durr, C. How do seed and seedling traits influence germination and emergence parameters in crop species? A comparative analysis. Seed Sci. Res. 2016, 26, 317-331. [CrossRef]

15. Baskin, C.C.; Baskin, J.M. Seeds; Academic Press: San Diego, CA, USA, 2014; p. 666.

16. Matthies, D. Plasticity of reproductive components at different stages of development in the annual plant Thlaspi arvense L. Oecologia 1990, 83, 105-116. [CrossRef] [PubMed]

17. Cernac, A.; Andre, C.; Hoffmann-Benning, S.; Benning, C. WRI1 is required for seed germination and seedling establishment. Plant Physiol. 2006, 141, 745-757. [CrossRef] [PubMed]

18. Gesch, R.W.; Royo-Esnal, A.; Edo-Tena, E.; Recasens, J.; Isbell, T.; Forcella, F. Growth environment but not seed position on the parent plant affect seed germination of two Thlaspi arvense L. populations. Ind. Crops Prod. 2016, 84, 241-247. [CrossRef]

19. Menegat, A.; Milberg, P.; Nilsson, A.T.S.; Andersson, L.; Vico, G. Soil water potential and temperature sum during reproductive growth control seed dormancy in Alopecurus myosuroides Huds. Ecol. Evol. 2018, 8, 7186-7194. [CrossRef]

20. Bradford, K.J. Applications of hydrothermal time to quantifying and modeling seed germination and dormancy. Weed Sci. 2002, 50, 248-260. [CrossRef]

21. Gesch, R.W.; Archer, D.W. Influence of sowing date on emergence characteristics of maize seed coated with a temperature-activated polymer. Agron. J. 2005, 97, 1543-1550. [CrossRef]

22. Guillemin, J.P.; Gardarin, A.; Granger, S.; Reibel, C.; Munier-Jolain, N.; Colbach, N. Assessing potential germination period of weeds with base temperatures and base water potentials. Weed Res. 2013, 53, 76-87. [CrossRef]

23. Braza, R.; García, M.B. Spreading recruitment over time to cope with environmental variability. Plant Ecol. 2011, 212, 283-292. [CrossRef]

24. Liu, Y.; Dong, H.; Liu, T.; Wang, H.; Wang, R.; Ma, Q.; Zhao, W.; Li, Q. Relationship between seed germination and invasion of Ambrosia artemisiifolia and A. trifida at different positions. Acta Ecol. Sin. 2019, 39, 9079-9088.

25. Matthews, S.; Khajeh Hosseini, M. Mean germination time as an indicator of emergence performance in soil of seed lots of maize (Zea mays). Seed Sci. Technol. 2006, 34, 339-347. [CrossRef]

(C) 2020 by the authors. Licensee MDPI, Basel, Switzerland. This article is an open access article distributed under the terms and conditions of the Creative Commons Attribution (CC BY) license (http://creativecommons.org/licenses/by/4.0/). 